\title{
Fatty acids profiles of some Spanish wild vegetables
}

\section{Patricia Morales, ${ }^{1,2}$ Isabel C.F.R. Ferreira, ${ }^{1, *}$ Ana Maria Carvalho, ${ }^{1} M^{a}$ Cortes Sánchez-Mata, ${ }^{3}$ Montaña Cámara ${ }^{3}$, Javier Tardío $^{4}$}

${ }^{1}$ Centro de Investigação de Montanha, ESA, Instituto Politécnico de Bragança, Campus de Santa Apolónia, Apartado 1172, 5301-854 Bragança, Portugal.

${ }^{2}$ Dpto. de Ciencias de la Salud, Universidad Internacional Valenciana (VIU). Calle José Pradas Gallen, s/n 2ºiso, 12006 Castellón de la Plana, Spain

${ }^{3}$ Dpto. Nutrición y Bromatología II. Facultad de Farmacia. Universidad Complutense de Madrid (UCM). Pza Ramón y Cajal, s/n. E-28040 Madrid, Spain.

${ }^{4}$ Instituto Madrileño de Investigación y Desarrollo Rural, Agrario y Alimentario (IMIDRA). Finca "El Encín". Apdo. 127. E-28800 Alcalá de Henares, Spain.

*Author to whom correspondence should be addressed (e-mail: iferreira@ipb.pt; telephone +351-273-303219; fax +351-273-325405).

Running title: Fatty acids in Spanish wild vegetables 


\begin{abstract}
Polyunsaturated fatty acids play an important role in human nutrition, being associated with several health benefits. The analyzed vegetables, in spite of his low fat content, lower than $2 \%$, presents a high proportion of PUFA of $n-3, n-6$ and n-9 series, such as $\alpha$-linolenic, linoleic, and oleic acids, respectively. Wild edible plants contain in general a good balance of n-6 and n-3 fatty acids. The present study tries to contribute to the preservation and valorization of traditional food resources, studying the fatty acids profile of twenty wild vegetables by GC-FID. Results show that species in which leaves are predominant in their edible parts have in general the highest PUFA/SFA ratios: Rumex pulcher (5.44), Cichorium intybus (5.14) and Papaver rhoeas (5.00). Due to the low n-6/n-3 ratios of the majority of the samples, they can be considered interesting sources of n-3 fatty acids, especially those with higher total fat amount, such as Bryonia dioica, Chondrilla juncea or Montia fontana, with the highest contents of $\alpha$-linolenic acid $(67.78,56.27$ and 47.65\%, respectively). The wild asparaguses of Asparagus acutifolius and Tamus communis stand out for their linoleic acid content (42.29 and 42.45\%, respectively). All these features reinforce the interest of including wild plants in diet, as an alternative to the variety of vegetables normally used.
\end{abstract}

KEYWORDS: wild edible vegetables; Fatty acids; Gas-Chromatography; Nutritional parameters 


\section{INTRODUCTION}

Fatty acids play an important role in human nutrition. Particularly, unsaturated fatty acids are associated with a reduced risk of developing cardiovascular disease, inflammatory and autoimmune diseases such as asthma, Crohn's disease and arthritis, and certain cancers, including colon, breast and prostate cancers (Simopoulus, 2002). Most fatty acids can be synthesized in the body, but humans lack the enzymes required to produce the essential fatty acids, which must be acquired from the diet. Among polyunsaturated fatty acids (PUFA), n-3 and n-6 series fatty acids are the biosynthetic precursor of eicosanoids, which take part in a wide range of metabolic functions (Voet \& Voet, 2004). Essential fatty acids are the $\alpha$-linolenic acid (ALA, C18:3 n-3) and linoleic acid (LA, C18:2 n-6).

The beneficial effects attributed to the n-3 PUFA consist in their ability to replace arachidonic acid (AA, C20:4 n-6) in cardiovascular membranes, with an enrichment in eicosapentaenoic acid and the production of prostaglandin $I_{3}$, which is equipotent to prostacyclin as an anti-aggregatory agent. The amount of arachidonic acid depends on upon the outcome of ALA competing with LA for the enzymes involved in desaturation and elongation. Therefore the ratio of dietary ALA to LA is very important from a nutritional point of view (Guil-Guerrero \& Rodríguez-García, 1999).

It is recommended to consume a minimum of $1 \%$ energy as n-6 PUFA and $0.2 \%$ energy as n-3 PUFA. Adequate intakes for male adults must be around 14-17 g per day of LA and 1.6 g per day of ALA, whereas for females the adequate intakes are lower, around 11-12 g per day of LA and $1.1 \mathrm{~g}$ per day of ALA (Trumbo, 2002).

Unfortunately, the balance of n-3 and n-6 PUFA in Western diets has changed substantially over the last 100 years (Ward \& Singh, 2005), being n-6 fatty acids the predominant PUFA. 
The high amount of n-6 fatty acids present in the Western diet (mainly arachidonic acid) produce eicosanoid metabolic products as prostaglandins, thromboxanes, leukotrienes, hydroxy fatty acids, and lipoxins, which contribute to the formation of thrombus and atheromas, allergic and inflammatory disorders (Simopoulus, 2002).

As reported by Ward and Singh in 2005, a low ratio of n-6/n-3 fatty acids is desirable for reducing the risk of many chronic diseases of high prevalence in Western societies. Excessive amounts of n-6 PUFA, and consequently a very high n-6/n-3 ratio, promotes the pathogenesis of many diseases, whereas high levels of n-3 PUFA (a low n-6/n-3 ratio) exert protective effects. In the secondary prevention of cardiovascular disease, a ratio of $4 / 1$ was associated with a $70 \%$ decrease in total mortality. For this reason, food technologists are looking for methods to modify the fatty acid profile of a given food to achieve dietary improvements. Another option to improve the $n-6 / n-3$ ratio is to increase $n-3$ intake from its natural sources. The lipid fraction present in plants is rich in PUFA, such as LA and ALA, and in those MUFA of the n-9 series such as oleic acid (C18:1 n-9). According to Simopoulos (2002), foods from wild edible plants contain a good balance of n-6 and n-3 fatty acids. He pointed that wild vegetables contain much more ALA than cultivated ones (Simopoulos, 2002).

The consumption of wild vegetables in Spain, like in many other countries, has played an important role in complementing staple agricultural foods. Although the traditional use of noncultivated vegetables has decreased with the development of agriculture and global supply chains, some species are still consumed (Tardío et al., 2005, 2006; Tardío, 2010) as a part of our traditional behaviors and our Mediterranean diet. These pprevious research works have estimated the wild vegetable species most commonly used as food sources, by 
some populations groups (mainly rural populations). Based on these criteria, the species studied in the present work have been selected.

Recent epidemiological studies suggest a positive correlation between diets rich in vegetables and fruits, and a reduced incidence of chronic diseases (Lasheras et al., 2000). In this way, the recovering of some of our ancestors' habits, such as the consumption of wild vegetables, rich in PUFA such as LA and ALA, could be an important strategy to improve dietary health benefits. In addition to their nutritional and functional value, wild vegetables may enrich our present diet. There is a great variety of species that can be prepared and consumed in many different ways, fresh or processed.

Despite the existence of a few reports about fatty acids in some wild species, such as Foeniculum vulgare from Portugal (Barros et al., 2010a), Cichorium intybus, Foeniculum vulgare, Scolymus hispanicus, Silene vulgaris, Sonchus oleraceus, Papaver rhoeas and Taraxacum sp.pl. from Greece (Vardavas et al., 2006), only one report on Silene vulgaris, Sonchus oleraceus and Beta maritima has been published from Spanish samples (Alarcón et al. 2006; Guil et al., 1996).

The present study aims to increase the knowledge on the fatty acids profile of twenty Spanish wild vegetables as a contribution to the preservation and valorization of these traditional vegetable resources.

\section{MATERIALS AND METHODS}

\section{Plant material}

According the data obtained of present food uses obtained in a previous ethnobotanical review (Tardío et al., 2006), twenty wild vegetables among the most commonly used in 
Spain were chosen. As shown in Table 1, the edible parts harvested and analyzed were different depending on the species. The young stems with leaves and the basal leaves (sometimes peeled leaving only the midribs) were the most common parts used for the majority of the vegetables. The young shoots, sometimes with the little leaves (not yet fully expanded), were the edible part analyzed in the case of the four "wild asparagus" (Asparagus acutifolius, Humulus lupulus, Tamus communis and Bryonia dioica). Finally, in the case of the wild leek (Allium ampeloprasum), the edible part was the bulb with the bottom of the leaves. These edible parts were those reported in the ethnobotanical surveys.

As can be seen in Table 1, Anchusa azurea, Rumex pulcher, Beta maritima, Allium ampeloprasum, Asparagus acutifolius, Humulus lupulus, Bryonia dioica, Tamus communis are traditionally consumed cooked, whereas Chondrilla juncea, Taraxacum obovatum, Montia fontana, Rumex papillaris and Apium nodiflorum are normally consumed fresh, mainly in salads. Some of them (Cichorium intybus, Silene vulgaris, Scolymus hispanicus, Silybum marianum, Sonchus oleraceus, Papaver rhoeas and Foeniculum vulgare) could be traditionally used in both forms, though much more frequently were consumed cooked.

The vegetable samples were gathered in the spring of 2007 and 2008 from two wild populations of each species in Central Spain in order to take into account the geographical and environmental variability. According to consumers' preferences, each vegetable sample was gathered at the best moment of harvesting that is, in general, when the plants reach the maximum development before flowering, being still tender. They were collected from the middle of March to late May. Different specimens of each species were randomly chosen from each population. At least $500 \mathrm{~g}$ of edible portion of each sample was gathered, 
cleaned and prepared, packed in plastic bags, and transported to the laboratories in a cold system within a day. Samples were immediately homogenized in a laboratory blender and were lyophilized (Telstar lyoQuest HT-40 Beijer electronics), keeping at $-20{ }^{\circ} \mathrm{C}$, in a dark, dry ambient.

Tests were performed in freeze-dried mixed samples joining the four samples gathered for each species (2 from 2007 and 2 from 2008).

\section{Reagents}

The fatty acids methyl ester (FAME) reference standard mixture 37 (standard 47885-U) as well as other individual fatty acid isomers, were obtained from Sigma (St. Louis, MO, USA). All other chemicals and solvents were of analytical grade and purchased from common sources. Water was treated in a Milli-Q water purification system (TGI Pure Water Systems, USA).

\section{Total fat and fatty acids profile}

The total fat content was determined by extracting a known amount of dry sample (around 3 g) with petroleum ether, using a Soxhlet apparatus, according to AOAC procedures (1995). Results were expressed in g per $100 \mathrm{~g}$ of fresh weight (fw).

Fatty acids were determined by gas-liquid chromatography with flame ionization detection (GC-FID)/capillary column as described previously (Barros et al., 2010b), after the following trans-esterification procedure: fatty acids were methylated with $5 \mathrm{~mL}$ of methanol:sulphuric acid:toluene 2:1:1 (v:v:v), during at least $12 \mathrm{~h}$ in a bath at $50{ }^{\circ} \mathrm{C}$ and $160 \mathrm{rpm}$; then $3 \mathrm{~mL}$ of deionised water were added, to obtain phase separation; the FAME were recovered with $3 \mathrm{~mL}$ of diethyl ether by shaking in vortex, and the upper phase was 
passed through a micro-column of sodium sulphate anhydrous, in order to eliminate the water; the sample was recovered in a vial with Teflon, and before injection the sample was filtered with $0.2 \mu \mathrm{m}$ nylon filter from Milipore. The equipment was a DANI model GC 1000 with a split/splitless injector and a FID. The column used was a $30 \mathrm{~m} \times 0.32 \mathrm{~mm}$ i.d., $0.25 \mu \mathrm{m}, 50 \%$ cyanopropyl-methyl-50\% phenylmethylpolysiloxane (Macherey-Nagel, Duren, Germany). The oven temperature program was as follows: the initial temperature of the column was $50{ }^{\circ} \mathrm{C}$, held for $2 \mathrm{~min}$, then a $10{ }^{\circ} \mathrm{C} / \mathrm{min}$ ramp to $240^{\circ} \mathrm{C}$ and held for 11 min. The carrier gas (hydrogen) flow rate was $4.0 \mathrm{~mL} / \mathrm{min}(0.61 \mathrm{bar})$, measured at $50{ }^{\circ} \mathrm{C}$. Split injection (1:40) was carried out at $250^{\circ} \mathrm{C}$. Fatty acid identification was made by comparing the relative retention times of FAME peaks from samples with standards. The results were recorded and processed using CSWDataApex 1.7 software and expressed in relative percentage of each fatty acid.

\section{Statistical analysis}

Analysis of variance (ANOVA), followed by Turkey's test, was conducted using Statgraphics Plus 5.1 software to analyze data at the $95 \%$ confidence level. Values were expressed as means of triplicate analyses and corresponding standard deviations.

\section{RESULTS AND DISCUSSION}

\section{Total fat and individual fatty acids content}

The individual fatty acids content and total fat of the twenty wild vegetables analyzed are presented in Table 2. All the studied samples showed a fat content lower than $2 \mathrm{~g} / 100 \mathrm{~g}$ fw 
being the lowest one Silybum marianum $(0.26 \mathrm{~g} / 100 \mathrm{~g}$ fw). Otherwise, the highest fat levels were found in Montia fontana, with $1.91 \mathrm{~g} / 100 \mathrm{~g}$ fw.

Thirty different fatty acids were identified and quantified. The main fatty acids found were $\alpha$-linolenic (ALA, C18:3n3), linoleic (LA, C18:2n6) and palmitic (PA, C16:0) acid, except for Sonchus oleraceus in which $\gamma$-linolenic acid (GLA, C18:3n6) predominated (Table 2). Moreover, in the samples where the edible parts were the basal leaves and the young stems with leaves, the major fatty acid was $\alpha$-linolenic (ALA, C18:3n3), apart from Foeniculum vulgare, with a quite similar proportion of linoleic acid (LA, C18:2n6). However, in young shoots samples depend on the species. LA was the major fatty acid in Asparagus acutifolius and Tamus communis, but in Humulus lupulus and Bryonia dioica the predominant was ALA, especially in the latter that almost reach $70 \%$ of the total fatty acid content (see Table 2).

PA is one of the most common saturated fatty acids found in animals and plants. The World Health Organization claims there is evidence that dietary intake of PA increases the risk of developing cardiovascular diseases. On the contrary, French et al. demonstrated in 2002 that PA has no hypercholesterolemic effect if the intake of LA is greater than $4.5 \%$ of energy. ALA is abundant in dark green plant leaves, and is the precursor of long chain n-3 PUFA such as eicosapentaenoic (EPA) and docosahexaenoic (DHA) acids (Voet \& Voet, 2004).

As shown in Table 2, the highest percentages of PA were found in Silybum marianum (28.69\%) whereas the lowest value appeared in Anchusa azurea (10.45\%). Other SFA found in all the samples were stearic acid (C18:0; highest levels observed in Silybum marianum, 5.05\%) and lignoceric acid (C24:0; highest value obtained in Silybum marianum, 3.36\%). Behenic acid (C22:0) was also identified in all the samples, except for 
Taraxacum obovatum, reaching its highest value in Humulus lupulus $(2.86 \%)$. The most abundant MUFA was oleic acid (C18:1) which appears in all the samples and ranged from $0.92 \%$ in Sonchus oleraceus to $7.39 \%$ in Allium ampelorasum. Among the PUFA the predominant were LA and ALA. The first one (LA) was identified in all the samples, ranging from $6.48 \%$ in Bryonia dioica to $53.45 \%$ in Allium ampelorasum. The latter (ALA) reached the highest values in Bryonia dioica (67.78\%), followed by Anchusa azurea (64.74\%) and Papaver rhoeas (64.97\%), not being detected in Allium ampeloprasum and Sonchus oleraceus. Furthermore, it is important to highlight the presence of other PUFA such as eicosatrienoic (ETA, C20:3n6), eicosapentanoic (EPA, C20:5n3) and docosahexanoic (DHA, C22:6n3) acids, the latter only identified in Foeniculum vulgare (Table 2).

In general, our results seem to be in agreement with other reports that have studied some wild vegetables in common, such as Foeniculum vulgare (Barros et al., 2010a; Vardavas et al., 2006), Beta maritima (Guil et al., 1996), Silene vulgaris (Alarcón et al., 2006), Sonchus oleraceus (Vardavas et al., 2006; Guil et al., 1996), Taraxacum sp., Scolymus hispanicus and Cichorium intybus (Vardavas et al., 1996). All of these reports have found the same three main fatty acids (PA, LA, ALA), being the amount of $\alpha$-linolenic acid around 30-50\%

Figure 1 shows the fatty acid profile found in Tamus communis, which is similar to the other wild vegetables studied. Figure 2 illustrate the fatty acid profile of Sonchus oleraceus, a bit different due to its high content in $\gamma$-linolenic acid (GLA, C18:3n6). The level of this fatty acid found in this species (66.31\%) do not agree with the works of Vardavas et al. (2006) and Guil et al. (1996) that reported ALA as major fatty acid (54.5\% and 43.6\% respectively) in samples from Greece in the first one and from Central Spain in the latter. 
GLA is a metabolite of linoleic acid (LA, 18:2n6) and the first intermediate in the conversion of LA to arachidonic acid (AA, 20:4n6) (Barceló-Coblijn \& Murphy, 2009). The high content of GLA in Sonchus oleraceus could be due to an extremely high activity of $\Delta^{6}$-desaturase, which transform LA to GLA in the AA metabolic conversion. This is in agreement with the results obtained for Sonchus fatty acids, in which the LA content is unnormally low (13.78\%). In this way, Sonchus oleraceous could be considered as a source of GLA, an unusual fatty acid in plants, highly, appreciated because of its nutritional and medical benefit (Horrobin, 1992).

We have also compared our data with those published for some species, which are cultivated as well, such as Foeniculum vulgare and Cichorium intybus, and with other closely related species as Asparagus officinalis and Taraxacum officinale (Souci et al., 2008). PA has been reported in all the species, LA was the major fatty acid in Foeniculum vulgare, Cichorium intybus and Asparagus officinalis, whereas in Taraxacum officinale the major fatty acid was ALA. These data does not completely agree with our results except in the case of wild Cichorium intybus, with ALA as the major fatty acid. This could be due to the extremely different growing conditions and shows the higher amount of n-3 fatty acid present in some wild vegetables than in cultivated ones.

\section{Saturated and unsaturated fatty acids and $n-6 / n-3$ ratio}

The percentages of each group of fatty acids (SFA, MUFA and PUFA) and PUFA/SFA and n-6/n-3 ratios, calculated for the twenty wild vegetables studied, are shown in Table 3 . As can be seen in Table 3, Silybum marianum revealed the highest value of total SFA (43.53\%), while Rumex pulcher showed the lowest one (14.77\%), though bearing in mind the much lower total fat of the first one than the latter $(0.26$ and $0.72 \mathrm{~g} / 100 \mathrm{~g} \mathrm{fw}$, 
respectively) the total amount could be similar. As for total MUFA, Rumex papillaris presented the highest value (9.03\%) in contrast to Sonchus oleraceus and Tamus communis (0.92\%). Regarding total PUFA content, Cichorium intybus showed the highest value (82.09\%), while Silybum marianum revealed the lowest one (52.61\%).

Taking into account the species grouped by their edible part (see Table 1), no clear differences appeared into the different groups. However, as can be observed in Table 3, the species whose edible part include the stems, like the young stems with leaves (Apium nodiflorum, Foeniculum vulgare, Montia fontana and Silene vulgaris) or the young shoots (Asparagus acutifolius, Humulus lupulus, Tamus communis and Bryonia dioica), and those whose leaves are peeled (Scolymus hispanicus and Silybum marianum) seem to have a higher percentage of SFA than those species whose edible part are the basal leaves $(\mathrm{p}<0.05)$. Our results also show that those samples in which leaves are predominant in their edible parts have in general the highest amounts of PUFA. The group of bulbs only represented by Allium ampeloprasum has also one of the highest relative values of SFA.

A low ratio of PUFA to SFA in the diet (lower than 0.45) might be an important risk factor for coronary heart disease, while diets rich in n-6 PUFA, but low SFA are cardio-protective (Russo, 2009). As can be seen in Table 3 all the analyzed samples revealed ratios higher than 1.2, particularly Rumex pulcher (5.44), Cichorium intybus (5.14) and Papaver rhoeas (5.00) that reached the highest values. In fact, the mortality rate from cardiovascular disease is very low in Mediterranean countries where the 'typical' traditional diet is low in SFA and high in PUFA. Although the diets of Mediterranean countries can vary, MUFA typically account for 16-29\% of energy intake (Kris-Etherton, 1999). Nevertheless, we need to increase our consumption of long chain n-3 PUFA and decrease intake of SFA. 
It is becoming increasingly clear that both $n-3$ and n-6 PUFA have independent health effects in the body, and as intakes of n-6 PUFA are within the guidelines for a healthy diet, concerns about the n- 6 to n-3 ratio are driven by low intakes of n-3 rather than high intakes of n-6 (Ward \& Singh, 2005). Simopoulos (2002) reported that n-6/n-3 ratios of 2-3/1 suppressed inflammation in patients with rheumatoid arthritis, and a ratio of $5 / 1$ had a beneficial effect on patients with asthma, whereas a ratio of $10 / 1$ had adverse consequences. Furthermore, the optimal balance between dietary ALA and LA, which are the two main fatty acids influencing this ratio, may contributed to reduce the prevalence of asthma disease (Oddy et al., 2004), may prevent thrombosis and atherosclerosis (Hu et al., 2001) and reduce potential lung cancer (Xia et al., 2005). Therefore, it is interesting to analyze the $n-6 / n-3$ ratios of the studied wild vegetables, since they have played an important role in traditional nutrition. As shown in Table 3, all the samples presented low levels for n-6/n-3 ratio, with the exceptions of Allium ampeloprasum and Sonchus oleraceus which revealed a really high value (99.59 and 511.5, respectively) and proved to be a good source of n-6 fatty acids, such as LA (53\%) or GLA (66 \%). The unusual value obtained in the Allium sample in comparison with the other vegetables may be probably due to be a different plant organ. The edible part of Allium ampeloprasum is a bulb with the bottom of the leaves, with fleshy storage tissues, while the other samples are aerial (aboveground) plant organs. Also Sonchus oleraceus presented a high n-6/n-3 ratio due to its extremely high GLA. For the rest of the vegetables, the n- $6 / n-3$ ratio was below 3 in the majority of the samples, i.e. the n-3 fatty acids predominated.

\section{Conclusions}


This study confirms that wild leafy vegetables can be an interesting source of essential fatty acids. They often contain higher amounts than many cultivated species.

Our results also show that those samples in which leaves are predominant in their edible parts have in general the highest amounts of PUFA, standing out Rumex pulcher, Cichorium intybus and Papaver rhoeas with the highest values for PUFA/SFA ratio.

Montia fontana, Chondrilla juncea, Bryonia dioica or Silene vulgaris showed the highest contents of $\alpha$-linolenic acid. They can contribute to improve the unbalanced $n-6 / n-3$ ratio of our Western diet with the consequent health benefits that many authors have claimed. Though the loss of these fatty acids in cooked vegetables should be better studied, and those species that are usually eaten raw, such as Montia fontana and Chondrilla juncea deserve a special mention.

All these features reinforce the interest of including wild plants in diet, as an alternative among the variety of vegetables normally used, and strengthen with new scientific evidence the empirical regional practices of wild species' consumption.

\section{Acknowledgements}

The authors are grateful to ERDF and the Spanish Ministry of Education and Science (research project CGL2006-09546/BOS) and to Foundation for Science and Technology (Portugal) for financial support. The authors also thank to Ramón Morales, Manuel Pardo de Santayana, Susana González and María Molina for collaborating in the gathering and preparation of the samples.

\section{References}


Alarcón R., Ortiz L.T. and García P. (2006). Nutrient and fatty acid composition of wild edible bladder campion populations [Silene vulgaris (Moench.) Garcke]. International Journal of Food Science and Technology 41: 1239-1242.

AOAC (1995). Official Methods of Analysis, $16^{\text {th }}$ ed. Association Analytical Chemistry, Arlington, VA.

Barceló-Coblijn G. and Murphy E.J. (2009). Alpha-linolenic acid and its conversion to longer chain n-3 fatty acids: Benefits for human health and a role in maintaining tissue n-3 fatty acid levels. Progress in Lipid Research 48: 355-374.

Barros L., Carvalho A.M. and Ferreira I.C.F.R. (2010a). The nutritional composition of fennel (Foeniculum vulgare): Shoots, leaves, stems and inflorescences. LWT- Food Science and Technology 43: 814-818.

Barros L., Carvalho A.M. and Ferreira I.C.F.R. (2010b). Leaves, flowers, immature fruits and leafy flowered stems of Malva sylvestris: A comparative study of the nutraceutical potential and composition. Food and Chemical Toxicology 48: 14661472.

French M.A., Sundram K. and Clandinin M.T. (2002). Cholesterolaemic effect of palmitic acid in relation to other dietary fatty acids. Asia Pacific Journal of Clinical Nutrition 11: S401- 407.

Guil J.L., Torija M.E., Giménez J.J. and Rodríguez I. (1996). Identification of fatty acid in edible wild plants by gas chromatography. Journal of Chromatography A 719: 229235.

Guil-Guerrero J.L. and Rodríguez-García I. (1999). Lipids classes, fatty acids and carotenes of the leaves of six edible wild plants. European Food Research Technology 209: 313-316. 
Horrobin D.F. (1992). Nutritional and medical importance of gamma-linolenic acid. Prog. Lipid Res. 31(2): 163-194.

Hu F., Manson J. and Willett W. (2001). Type of dietary fat and risk of coronary heart disease: a critical review. Journal of American College of Nutrition 20: 5-19.

Kris-Etherton P.M. (1999). Monounsaturated fatty acids and risk of cardiovascular disease. Circulation 100: 1253-1258.

Lasheras C., Fernandez S. and Patterson A.M. (2000). Mediterranean diet and age with respect to overall survival in institutionalized, nonsmoking elderly people. American Journal of Clinical Nutrition 71: 987-992.

Oddy W.H., De Klerk N.H., Kendall G.E., Mihrshahi S. and Peat J.K. (2004). Ratio of omega-6 to omega-3 fatty acids and childhood asthma. Journal of Asthma 41: 319326.

Simopoulus A.P. (2002). The importance of ratio of omega-6/omega-3 essential fatty acids. Biomedical Pharmacotherapy 56: 365-379.

Russo G.L. (2009). Dietary n-6 and n-3 polyunsaturated fatty acids: From biochemistry to clinical implications in cardiovascular prevention. Biochemical Pharmacology 77: 937-946.

Souci S.W., Fachmann W. and Kraut G. (2008). Food Composition and Nutritional Tables. 7th revised and completed edition, Taylor \& Francis A CRC Press Book, USA.

Tardío J., Pascual H. and Morales R. (2005). Wild food plants traditionally used in the province of Madrid, Central. Economic Botany 59: 122-136.

Tardío J., Pardo de Santayana M. and Morales R. (2006). Ethnobotanical review of wild edible plants in Spain. Botanic Journal of the Linnean Society 152: 27-71. 
Tardío J. (2010). Spring is coming: The gathering and consumption of wild vegetables in Spain. In M. Pardo-de-Santayana, A. Pieroni, R. Puri. Ethnobotany in the New Europe. UK: Berghahn Books, 211-237.

Trumbo P. (2002). Dietary References intakes for Energy, Carbohydrate, Fiber, Fat, Fatty Acids, Cholesterol, Protein and Amino Acids. Journal of the American Dietetic Association 102: 1621-1630.

Vardavas C.I., Majchrzak D., Wagner K.H., Elmadfa I. and Katafos A. (2006). Lipid concentrations of wild edible greens in Crete. Food Chemistry 99: 822-834.

Voet D. and Voet J.G. (2004). Biochemistry, 3erd ed. Wiley \& Sons, Hoboken, NJ.

Ward O.P. and Singh A. (2005). Omega-3/6 fatty acids: Alternative sources of production. Process Biochemistry 40: 3627-3652.

Xia S.H., Wang J. and Kang J.X. (2005). Decreased n-6/n-3 fatty acid ratio reduces the invasive potential of human lung cancer cells by down-regulation of cell adhesion/invasion-related genes. Carcinogenesis 26: 779-84. 
Table 1. Wild vegetables species, edible part analyzed and mode of consumption [7].

\begin{tabular}{|c|c|c|}
\hline Species & Edible parts analyzed & Mode of consumption \\
\hline Apium nodiflorum (L.) Lag. & Young stems with leaves & Raw in salads \\
\hline Foeniculum vulgare Mill. & Young stems with leaves & Raw (snack, salads) or cooked \\
\hline Montia fontana L. & Young stems with leaves & Raw in salads \\
\hline Silene vulgaris (Moench) Garcke & Young stems with leaves & Cooked, seldom raw in salads \\
\hline Anchusa azurea Mill. & Basal leaves & Cooked \\
\hline Beta maritima L. & Basal leaves & Cooked \\
\hline Cichorium intybus L. & Basal leaves & Raw (salads) or cooked \\
\hline Rumex papillaris Boiss. \& Reut. & Basal leaves & Raw in salads \\
\hline Rumex pulcher L. & Basal leaves & Cooked \\
\hline Taraxacum obovatum (Willd.) DC. & Basal leaves & Raw in salads \\
\hline Chondrilla juncea L. & Basal leaves & Raw in salads \\
\hline Papaver rhoeas L. & Basal leaves & Cooked, seldom raw in salads \\
\hline Sonchus oleraceus L. & Basal leaves & Raw (salads) or cooked \\
\hline Scolymus hispanicus $\mathrm{L}$ & Peeled basal leaves & Cooked, seldom raw in salads \\
\hline Silybum marianum (L.) Gaertn. & Peeled basal leaves/young shoots & Cooked, seldom raw in salads \\
\hline Asparagus acutifolius L. & Young shoots & Cooked \\
\hline Humulus lupulus L. & Young shoots with little leaves & Cooked \\
\hline Tamus communis L. & Young shoots with little leaves & Cooked \\
\hline Bryonia dioica Jacq. & Young shoots with little leaves & Cooked \\
\hline Allium ampeloprasum L. & Bulbs and bottom of leaves & Cooked \\
\hline
\end{tabular}


Table 2. Composition in fatty acids (percentages) and total fat (g/100 $\mathrm{g} \mathrm{fw}$ ) of the studied wild edible vegetables.

\begin{tabular}{|c|c|c|c|c|c|c|c|c|c|c|}
\hline & $\begin{array}{c}\text { Allium } \\
\text { ampeloprasum }\end{array}$ & $\begin{array}{c}\text { Anchusa } \\
\text { azurea }\end{array}$ & $\begin{array}{c}\text { Apium } \\
\text { nodiflorum }\end{array}$ & $\begin{array}{l}\text { Asparagus } \\
\text { acutifolius }\end{array}$ & $\begin{array}{c}\text { Beta } \\
\text { maritima }\end{array}$ & $\begin{array}{c}\text { Bryonia } \\
\text { dioica }\end{array}$ & $\begin{array}{c}\text { Chondrilla } \\
\text { juncea }\end{array}$ & $\begin{array}{c}\text { Cichorium } \\
\text { intybus }\end{array}$ & $\begin{array}{c}\text { Foeniculum } \\
\text { vulgare }\end{array}$ & $\begin{array}{l}\text { Humulus } \\
\text { lupulus }\end{array}$ \\
\hline C6:0 & nd & nd & nd & nd & nd & $0.02 \pm 0.01$ & $0.10 \pm 0.00$ & nd & $0.41 \pm 0.02$ & $0.20 \pm 0.05$ \\
\hline $\mathrm{C} 8: 0$ & $0.33 \pm 0.07$ & nd & $0.73 \pm 0.09$ & $0.21 \pm 0.05$ & $0.09 \pm 0.02$ & $0.08 \pm 0.05$ & $0.04 \pm 0.00$ & $0.06 \pm 0.01$ & $0.42 \pm 0.02$ & $0.05 \pm 0.01$ \\
\hline C10:0 & $0.21 \pm 0.02$ & $0.07 \pm 0.02$ & $0.20 \pm 0.01$ & $0.39 \pm 0.06$ & $0.08 \pm 0.01$ & $0.05 \pm 0.03$ & $0.05 \pm 0.01$ & $0.07 \pm 0.02$ & $0.12 \pm 0.01$ & nd \\
\hline C11:0 & $0.05 \pm 0.01$ & $0.01 \pm 0.00$ & $0.29 \pm 0.01$ & nd & nd & $0.00 \pm 0.00$ & $0.04 \pm 0.00$ & $0.01 \pm 0.00$ & nd & nd \\
\hline C12:0 & $0.18 \pm 0.03$ & $0.07 \pm 0.02$ & nd & $0.45 \pm 0.05$ & $0.06 \pm 0.00$ & $0.08 \pm 0.04$ & $0.05 \pm 0.02$ & $0.05 \pm 0.01$ & $0.08 \pm 0.01$ & $0.05 \pm 0.01$ \\
\hline $\mathrm{C} 13: 0$ & $0.04 \pm 0.02$ & $0.01 \pm 0.00$ & nd & nd & nd & nd & nd & $0.01 \pm 0.00$ & $0.03 \pm 0.01$ & nd \\
\hline C14:0 & $0.64 \pm 0.03$ & $0.35 \pm 0.02$ & $0.69 \pm 0.09$ & $0.72 \pm 0.06$ & $0.42 \pm 0.00$ & $0.33 \pm 0.09$ & $0.58 \pm 0.05$ & $0.37 \pm 0.08$ & $0.83 \pm 0.04$ & $0.49 \pm 0.03$ \\
\hline C14:1 & nd & $0.16 \pm 0.02$ & $0.92 \pm 0.09$ & nd & $0.06 \pm 0.04$ & $0.06 \pm 0.02$ & nd & $0.08 \pm 0.09$ & $0.69 \pm 0.01$ & $0.08 \pm 0.01$ \\
\hline $\mathrm{C} 15: 0$ & $0.55 \pm 0.03$ & $0.12 \pm 0.00$ & $0.35 \pm 0.18$ & $0.63 \pm 0.08$ & $0.15 \pm 0.03$ & $0.17 \pm 0.04$ & $0.22 \pm 0.03$ & $0.22 \pm 0.04$ & $0.25 \pm 0.04$ & $0.10 \pm 0.04$ \\
\hline C16:0 & $26.42 \pm 0.30$ & $10.45 \pm 0.62$ & $16.29 \pm 0.96$ & $28.65 \pm 0.02$ & $11.03 \pm 0.15$ & $17.01 \pm 1.22$ & $12.96 \pm 0.47$ & $10.64 \pm 0.63$ & $17.37 \pm 0.28$ & $19.52 \pm 0.61$ \\
\hline $\mathrm{C} 16: 1$ & $0.22 \pm 0.02$ & $0.14 \pm 0.01$ & $1.10 \pm 0.32$ & nd & $0.11 \pm 0.00$ & $0.10 \pm 0.00$ & $0.11 \pm 0.00$ & $0.13 \pm 0.04$ & $0.15 \pm 0.01$ & $0.46 \pm 0.01$ \\
\hline $\mathrm{C} 17: 0$ & $0.89 \pm 0.13$ & $0.22 \pm 0.01$ & nd & $0.72 \pm 0.01$ & $0.21 \pm 0.01$ & $0.39 \pm 0.02$ & $0.38 \pm 0.02$ & $0.24 \pm 0.01$ & $0.29 \pm 0.00$ & $0.34 \pm 0.02$ \\
\hline C18:0 & $3.30 \pm 0.35$ & $1.67 \pm 1.19$ & $1.77 \pm 0.33$ & $2.70 \pm 0.52$ & $1.67 \pm 0.01$ & $2.66 \pm 0.04$ & $2.17 \pm 0.03$ & $1.39 \pm 0.06$ & $1.55 \pm 0.03$ & $1.60 \pm 0.05$ \\
\hline C18:1n9 & $7.39 \pm 0.42$ & $2.20 \pm 0.00$ & $3.33 \pm 0.02$ & $4.87 \pm 0.07$ & $3.51 \pm 0.01$ & $1.21 \pm 0.03$ & $1.91 \pm 0.01$ & $1.61 \pm 0.04$ & $2.14 \pm 0.08$ & $1.88 \pm 0.10$ \\
\hline C18:2n6 & $53.45 \pm 0.27$ & $12.16 \pm 0.11$ & $24.60 \pm 0.77$ & $42.29 \pm 0.02$ & $21.28 \pm 0.04$ & $6.48 \pm 0.10$ & $19.92 \pm 0.17$ & $21.14 \pm 0.06$ & $37.01 \pm 0.13$ & $29.72 \pm 0.85$ \\
\hline C18:3n6 & nd & $1.46 \pm 0.03$ & nd & nd & nd & nd & $0.13 \pm 0.00$ & $0.33 \pm 0.00$ & nd & $0.36 \pm 0.01$ \\
\hline $\mathrm{C} 18: 3 \mathrm{n} 3$ & nd & $64.74 \pm 0.23$ & $43.46 \pm 0.08$ & $14.01 \pm 0.54$ & $57.80 \pm 0.03$ & $67.78 \pm 1.10$ & $56.27 \pm 0.13$ & $60.45 \pm 0.41$ & $35.54 \pm 0.52$ & $38.16 \pm 0.02$ \\
\hline C20:0 & $0.80 \pm 0.22$ & $1.64 \pm 0.17$ & $0.34 \pm 0.04$ & $0.45 \pm 0.14$ & $0.46 \pm 0.04$ & $0.52 \pm 0.00$ & $2.31 \pm 0.15$ & $0.63 \pm 0.00$ & $0.76 \pm 0.01$ & $2.34 \pm 0.15$ \\
\hline C20:1 & nd & $0.17 \pm 0.01$ & nd & nd & $0.25 \pm 0.00$ & nd & $0.04 \pm 0.00$ & $0.05 \pm 0.00$ & $0.10 \pm 0.02$ & $0.13 \pm 0.01$ \\
\hline $\mathrm{C} 20: 2$ & $0.17 \pm 0.02$ & nd & nd & nd & nd & nd & nd & nd & $0.12 \pm 0.01$ & $0.34 \pm 0.09$ \\
\hline $\mathrm{C} 20: 3 \mathrm{n} 6$ & nd & $1.69 \pm 1.18$ & $2.64 \pm 2.85$ & nd & nd & nd & nd & nd & nd & nd \\
\hline $\mathrm{C} 20: 3 \mathrm{n} 3+\mathrm{C} 21: 0$ & $0.44 \pm 0.04$ & $0.21 \pm 0.02$ & nd & nd & $0.16 \pm 0.03$ & $0.16 \pm 0.01$ & $0.21 \pm 0.03$ & $0.17 \pm 0.04$ & $0.14 \pm 0.04$ & $0.44 \pm 0.04$ \\
\hline $\mathrm{C} 20: 5 \mathrm{n} 3$ & $0.10 \pm 0.01$ & nd & nd & nd & nd & nd & nd & nd & nd & nd \\
\hline $\mathrm{C} 22: 0$ & $2.75 \pm 0.05$ & $1.25 \pm 0.06$ & $1.22 \pm 0.05$ & $2.22 \pm 0.03$ & $1.02 \pm 0.03$ & $1.04 \pm 0.05$ & $1.54 \pm 0.21$ & $1.00 \pm 0.19$ & $1.02 \pm 0.03$ & $2.86 \pm 0.23$ \\
\hline $\mathrm{C} 22: \ln 9$ & nd & $0.07 \pm 0.01$ & nd & nd & $0.06 \pm 0.00$ & $0.26 \pm 0.03$ & nd & nd & nd & nd \\
\hline $\mathrm{C} 22: 2$ & nd & nd & nd & nd & $0.09 \pm 0.01$ & nd & nd & nd & nd & nd \\
\hline $\mathrm{C} 22: 6 \mathrm{n} 3$ & nd & nd & nd & nd & nd & nd & nd & nd & $0.14 \pm 0.05$ & nd \\
\hline $\mathrm{C} 23: 0$ & $0.34 \pm 0.07$ & $0.02 \pm 0.03$ & nd & $0.36 \pm 0.17$ & $0.11 \pm 0.01$ & nd & $0.16 \pm 0.01$ & $0.14 \pm 0.00$ & $0.16 \pm 0.03$ & nd \\
\hline $\mathrm{C} 24: 0$ & $1.73 \pm 0.49$ & $0.72 \pm 0.09$ & $2.07 \pm 0.02$ & $1.33 \pm 0.31$ & $1.38 \pm 0.08$ & $1.58 \pm 0.21$ & $0.81 \pm 0.15$ & $1.16 \pm 0.05$ & $0.69 \pm 0.05$ & $0.89 \pm 0.54$ \\
\hline $\mathrm{C} 24: 1$ & nd & $0.40 \pm 0.03$ & nd & nd & nd & nd & nd & $0.08 \pm 0.09$ & nd & nd \\
\hline Total Fat & 0.51 & 0.93 & 0.74 & 0.99 & 0.70 & 1.39 & 1.50 & 0.92 & 0.76 & 1.08 \\
\hline
\end{tabular}

Caproic acid (C6:0); caprylic acid (C8:0); capric acid (C10:0); undecanoic acid (C11:0); lauric acid (C12:0); tridecanoic acid (C13:0); myristic acid (C14:0);

myristoleic acid (C14:1); pentadecanoic acid (C15:0); palmitic acid (C16:0); palmitoleic acid (C16:1); heptadecanoic acid (C17:0); stearic acid (C18:0); oleic acid (C18:1n9c); linoleic acid (C18:2n6c); $\gamma$-linolenic acid (C18:3n6); $\alpha$-linolenic acid (C18:3n3); arachidic acid (C20:0); eicosenoic acid (C20:1c); cis-11.14-

eicosadienoic acid (C20:2c); cis-8.11.14-eicostrienoic acid (C20:3n6); cis-11.14.17-eicosatrienoic acid and heneicosanoic acid (C20:3n3 + C21:0); cis-5. 8. 11.

14. 17-eicosapenstaenoic acid (C20:5n3); heneicosanoic acid (C21:0); behenic acid (C22:0); eruicic acid (C22:1n9); cis-13. 16- docosadienoic acid (C22:2); cis-

4. 7. 10. 13. 16. 19 - docosahexaenoic acid (C22:6n3); tricosanoic acid (C23:0); lignoceric acid (C24:0); nervonic acid (C24:1). nd: not detected. 
Table 2 (cont.). Composition in fatty acids (percentages) and total fat ( $\mathrm{g} / 100 \mathrm{~g} \mathrm{fw})$ of the studied wild edible vegetables.

\begin{tabular}{|c|c|c|c|c|c|c|c|c|c|c|}
\hline & $\begin{array}{l}\text { Montia } \\
\text { fontana }\end{array}$ & $\begin{array}{l}\text { Papaver } \\
\text { rhoeas }\end{array}$ & $\begin{array}{c}\text { Rumex } \\
\text { papillaris }\end{array}$ & $\begin{array}{l}\text { Rumex } \\
\text { pulcher }\end{array}$ & $\begin{array}{c}\text { Scolymus } \\
\text { hispanicus }\end{array}$ & $\begin{array}{c}\text { Silene } \\
\text { vulgaris }\end{array}$ & $\begin{array}{c}\text { Silybum } \\
\text { marianum }\end{array}$ & $\begin{array}{c}\text { Sonchus } \\
\text { oleraceus }\end{array}$ & $\begin{array}{c}\text { Tamus } \\
\text { communis }\end{array}$ & $\begin{array}{c}\text { Taraxacum } \\
\text { obovatum }\end{array}$ \\
\hline C6:0 & nd & $0.11 \pm 0.04$ & $0.05 \pm 0.02$ & $0.02 \pm 0.00$ & $0.22 \pm 0.00$ & $0.11 \pm 0.03$ & nd & $0.44 \pm 0.19$ & nd & nd \\
\hline $\mathrm{C} 8: 0$ & $0.05 \pm 0.01$ & $0.01 \pm 0.01$ & $0.02 \pm 0.01$ & $0.05 \pm 0.01$ & $0.39 \pm 0.07$ & $0.06 \pm 0.02$ & nd & $0.14 \pm 0.07$ & $0.05 \pm 0.00$ & $0.01 \pm 0.01$ \\
\hline C10:0 & $0.07 \pm 0.03$ & $0.06 \pm 0.02$ & $0.03 \pm 0.01$ & $0.12 \pm 0.01$ & $0.21 \pm 0.05$ & $0.05 \pm 0.02$ & $0.19 \pm 0.07$ & $0.14 \pm 0.05$ & $0.04 \pm 0.00$ & $0.09 \pm 0.01$ \\
\hline C11:0 & nd & $0.01 \pm 0.00$ & nd & $0.01 \pm 0.00$ & nd & $0.09 \pm 0.03$ & nd & nd & nd & $0.01 \pm 0.00$ \\
\hline C12:0 & $0.18 \pm 0.07$ & $0.14 \pm 0.04$ & $0.10 \pm 0.02$ & $0.23 \pm 0.02$ & $0.24 \pm 0.01$ & $0.44 \pm 0.14$ & $0.48 \pm 0.09$ & $0.15 \pm 0.03$ & $0.06 \pm 0.00$ & $0.35 \pm 0.05$ \\
\hline C13:0 & nd & $0.01 \pm 0.00$ & nd & $0.01 \pm 0.00$ & nd & $0.01 \pm 0.01$ & nd & nd & $0.01 \pm 0.00$ & nd \\
\hline $\mathrm{C} 14: 0$ & $0.60 \pm 0.14$ & $0.63 \pm 0.07$ & $0.51 \pm 0.35$ & $0.39 \pm 0.01$ & $0.79 \pm 0.00$ & $1.04 \pm 0.12$ & $0.99 \pm 0.32$ & $1.53 \pm 0.32$ & $0.15 \pm 0.00$ & $0.80 \pm 0.07$ \\
\hline C14:1 & $0.34 \pm 0.09$ & $0.22 \pm 0.01$ & $2.75 \pm 0.33$ & $0.14 \pm 0.14$ & nd & $0.87 \pm 0.04$ & nd & nd & $0.03 \pm 0.00$ & $0.25 \pm 0.01$ \\
\hline C15:0 & $0.36 \pm 0.05$ & $0.19 \pm 0.03$ & $0.74 \pm 0.04$ & $0.24 \pm 0.02$ & $0.57 \pm 0.05$ & $0.54 \pm 0.04$ & $1.04 \pm 0.00$ & $0.09 \pm 0.01$ & $0.22 \pm 0.00$ & $0.25 \pm 0.04$ \\
\hline C16:0 & $11.33 \pm 0.98$ & $9.66 \pm 0.39$ & $11.20 \pm 0.32$ & $9.30 \pm 0.11$ & $20.65 \pm 0.85$ & $18.15 \pm 0.37$ & $28.69 \pm 1.60$ & $10.43 \pm 0.70$ & $14.91 \pm 0.05$ & $11.83 \pm 0.09$ \\
\hline C16:1 & $0.34 \pm 0.03$ & $0.16 \pm 0.01$ & $0.20 \pm 0.09$ & $0.21 \pm 0.01$ & $1.43 \pm 0.15$ & $0.34 \pm 0.01$ & nd & nd & $0.15 \pm 0.00$ & $0.21 \pm 0.00$ \\
\hline C17:0 & $0.23 \pm 0.00$ & $0.24 \pm 0.00$ & $0.21 \pm 0.01$ & $0.33 \pm 0.00$ & $1.26 \pm 0.00$ & $0.21 \pm 0.02$ & $1.30 \pm 0.06$ & nd & $0.17 \pm 0.00$ & $0.57 \pm 0.01$ \\
\hline $\mathrm{C} 18: 0$ & $0.99 \pm 0.04$ & $1.46 \pm 0.01$ & $0.80 \pm 0.06$ & $1.73 \pm 0.03$ & $3.91 \pm 0.13$ & $1.85 \pm 0.01$ & $5.05 \pm 0.41$ & $1.58 \pm 0.15$ & $0.98 \pm 0.00$ & $2.45 \pm 0.03$ \\
\hline C18:1n9 & $6.05 \pm 0.42$ & $1.36 \pm 0.00$ & $5.80 \pm 0.14$ & $4.22 \pm 0.01$ & $6.41 \pm 0.07$ & $2.74 \pm 0.10$ & $3.86 \pm 0.10$ & $0.92 \pm 0.10$ & $4.57 \pm 0.01$ & $3.24 \pm 0.01$ \\
\hline $\mathrm{C} 18: 2 \mathrm{n} 6$ & $18.22 \pm 0.39$ & $16.53 \pm 0.01$ & $22.79 \pm 0.19$ & $17.03 \pm 0.16$ & $26.44 \pm 0.26$ & $22.26 \pm 0.35$ & $31.01 \pm 0.63$ & $13.78 \pm 0.61$ & $42.45 \pm 0.01$ & $17.64 \pm 0.08$ \\
\hline C18:3n6 & $0.40 \pm 0.01$ & nd & nd & nd & nd & $0.19 \pm 0.04$ & nd & $66.31 \pm 0.22$ & $0.90 \pm 0.01$ & $0.16 \pm 0.00$ \\
\hline $\mathrm{C} 18: 3 \mathrm{n} 3$ & $47.65 \pm 0.23$ & $64.98 \pm 0.07$ & $51.77 \pm 0.14$ & $62.97 \pm 0.03$ & $30.55 \pm 0.23$ & $44.68 \pm 0.64$ & $21.60 \pm 0.25$ & nd & $31.27 \pm 0.10$ & $58.53 \pm 0.23$ \\
\hline C20:0 & $9.45 \pm 1.72$ & $1.03 \pm 0.06$ & $0.27 \pm 0.15$ & $0.44 \pm 0.07$ & $1.58 \pm 0.24$ & $2.79 \pm 0.05$ & nd & $1.25 \pm 0.22$ & $0.22 \pm 0.01$ & $0.56 \pm 0.12$ \\
\hline C20:1 & $0.05 \pm 0.01$ & $0.05 \pm 0.01$ & $0.19 \pm 0.02$ & $0.14 \pm 0.01$ & $0.15 \pm 0.00$ & $0.06 \pm 0.02$ & nd & nd & $0.25 \pm 0.06$ & $0.09 \pm 0.02$ \\
\hline $\mathrm{C} 20: 2$ & nd & $0.20 \pm 0.14$ & $0.25 \pm 0.13$ & $0.15 \pm 0.04$ & $0.21 \pm 0.02$ & $0.19 \pm 0.00$ & nd & nd & $0.17 \pm 0.05$ & nd \\
\hline C20:3n6 & $0.71 \pm 0.55$ & nd & nd & nd & nd & nd & nd & nd & nd & nd \\
\hline $\mathrm{C} 20: 3 \mathrm{n} 3+\mathrm{C} 21: 0$ & $0.14 \pm 0.00$ & $0.15 \pm 0.01$ & $0.13 \pm 0.06$ & $0.16 \pm 0.09$ & $0.47 \pm 0.05$ & $0.17 \pm 0.02$ & nd & $0.14 \pm 0.04$ & $0.04 \pm 0.00$ & $0.22 \pm 0.02$ \\
\hline $\mathrm{C} 20: 5 \mathrm{n} 3$ & nd & nd & nd & $0.09 \pm 0.02$ & nd & nd & nd & nd & $0.04 \pm 0.01$ & nd \\
\hline $\mathrm{C} 22: 0$ & $1.53 \pm 0.33$ & $1.69 \pm 0.10$ & $0.76 \pm 0.04$ & $0.91 \pm 0.07$ & $2.31 \pm 0.13$ & $1.03 \pm 0.01$ & $2.43 \pm 1.27$ & $2.28 \pm 0.28$ & $1.01 \pm 0.01$ & $0.99 \pm 0.01$ \\
\hline $\mathrm{C} 22: \ln 9$ & $0.68 \pm 0.00$ & nd & $0.06 \pm 0.01$ & $0.07 \pm 0.02$ & nd & $0.34 \pm 0.03$ & nd & nd & $0.01 \pm 0.01$ & nd \\
\hline $\mathrm{C} 22: 2$ & nd & nd & $0.11 \pm 0.01$ & nd & nd & nd & nd & nd & $0.04 \pm 0.01$ & nd \\
\hline $\mathrm{C} 22: 6 \mathrm{n} 3$ & nd & nd & nd & nd & nd & nd & nd & nd & nd & nd \\
\hline $\mathrm{C} 23: 0$ & $0.06 \pm 0.01$ & $0.05 \pm 0.01$ & $0.05 \pm 0.02$ & $0.08 \pm 0.01$ & $0.32 \pm 0.21$ & $0.06 \pm 0.02$ & nd & nd & $0.11 \pm 0.00$ & $0.17 \pm 0.02$ \\
\hline $\mathrm{C} 24: 0$ & $0.58 \pm 0.06$ & $1.10 \pm 0.12$ & $1.18 \pm 0.04$ & $0.90 \pm 0.06$ & $1.72 \pm 0.08$ & $1.74 \pm 0.13$ & $3.36 \pm 0.30$ & $0.83 \pm 0.14$ & $2.14 \pm 0.07$ & $1.51 \pm 0.07$ \\
\hline $\mathrm{C} 24: 1$ & nd & nd & $0.05 \pm 0.01$ & $0.06 \pm 0.03$ & $0.20 \pm 0.10$ & nd & nd & nd & $0.05 \pm 0.01$ & $0.08 \pm 0.02$ \\
\hline Total Fat & 1.91 & 1.03 & 1.11 & 0.72 & 0.64 & 1.31 & 0.26 & 1.28 & 1.24 & 1.16 \\
\hline
\end{tabular}


Table 3. Nutritional fatty acids parameters in the wild vegetables studied. Different letters mean significant differences in each column $(\mathrm{p}<0.05)$.

\begin{tabular}{lccccc}
\hline & Total SFA & Total MUFA & Total PUFA & PUFA/SFA & $\mathrm{n}-6 / \mathrm{n}-3$ \\
\hline Apium nodiflorum & $23.94 \pm 1.56 \mathrm{ef}$ & $5.36 \pm 0.44 \mathrm{i}$ & $70.70 \pm 2.00 \mathrm{ef}$ & $2.96 \pm 0.28 \mathrm{de}$ & $0.63 \pm 0.05 \mathrm{a}$ \\
Foeniculum vulgare & $23.97 \pm 0.26 \mathrm{f}$ & $3.08 \pm 0.08 \mathrm{de}$ & $72.95 \pm 0.32 \mathrm{fg}$ & $3.04 \pm 0.05 \mathrm{de}$ & $1.03 \pm 0.02 \mathrm{a}$ \\
Montia fontana & $25.42 \pm 0.87 \mathrm{f}$ & $7.46 \pm 0.30 \mathrm{j}$ & $67.12 \pm 1.17 \mathrm{~d}$ & $2.64 \pm 0.14 \mathrm{~cd}$ & $0.40 \pm 0.02 \mathrm{a}$ \\
Silene vulgaris & $28.17 \pm 0.83 \mathrm{~g}$ & $4.35 \pm 0.14 \mathrm{gh}$ & $67.48 \pm 0.97 \mathrm{~d}$ & $2.40 \pm 0.10 \mathrm{c}$ & $0.50 \pm 0.00 \mathrm{a}$ \\
\hline Anchusa azurea & $16.59 \pm 0.82 \mathrm{ab}$ & $3.15 \pm 0.02 \mathrm{def}$ & $80.26 \pm 0.85 \mathrm{j}$ & $4.85 \pm 0.29 \mathrm{i}$ & $0.24 \pm 0.02 \mathrm{a}$ \\
Beta maritima & $16.68 \pm 0.02 \mathrm{ab}$ & $4.00 \pm 0.03 \mathrm{~g}$ & $79.33 \pm 0.01 \mathrm{ij}$ & $4.76 \pm 0.00 \mathrm{i}$ & $0.37 \pm 0.00 \mathrm{a}$ \\
Cichorium intybus & $15.96 \pm 0.52 \mathrm{a}$ & $1.95 \pm 0.00 \mathrm{bc}$ & $82.09 \pm 0.10 \mathrm{hi}$ & $5.14 \pm 0.05 \mathrm{ab}$ & $0.35 \pm 0.00 \mathrm{a}$ \\
Rumex papillaris & $15.91 \pm 0.11 \mathrm{a}$ & $9.03 \pm 0.30 \mathrm{k}$ & $75.05 \pm 0.27 \mathrm{gh}$ & $4.72 \pm 0.04 \mathrm{i}$ & $0.44 \pm 0.00 \mathrm{a}$ \\
Rumex pulcher & $14.77 \pm 0.09 \mathrm{a}$ & $4.83 \pm 0.15 \mathrm{hi}$ & $80.39 \pm 0.06 \mathrm{j}$ & $5.44 \pm 0.03 \mathrm{j}$ & $0.27 \pm 0.00 \mathrm{a}$ \\
Taraxacum obovatum & $19.58 \pm 0.28 \mathrm{~cd}$ & $3.67 \pm 0.04 \mathrm{efg}$ & $76.55 \pm 0.32 \mathrm{hi}$ & $3.91 \pm 0.07 \mathrm{~g}$ & $0.30 \pm 0.00 \mathrm{a}$ \\
Chondrilla juncea & $21.41 \pm 0.02 \mathrm{de}$ & $2.06 \pm 0.01 \mathrm{bc}$ & $76.53 \pm 0.02 \mathrm{j}$ & $3.57 \pm 0.00 \mathrm{fg}$ & $0.35 \pm 0.00 \mathrm{a}$ \\
Papaver rhoeas & $16.37 \pm 0.22 \mathrm{a}$ & $1.78 \pm 0.01 \mathrm{~b}$ & $81.85 \pm 0.23 \mathrm{j}$ & $5.00 \pm 0.08 \mathrm{ij}$ & $0.25 \pm 0.00 \mathrm{a}$ \\
Sonchus oleraceus & $18.85 \pm 0.73 \mathrm{bc}$ & $0.92 \pm 0.10 \mathrm{a}$ & $80.23 \pm 0.68 \mathrm{j}$ & $4.26 \pm 0.20 \mathrm{~h}$ & $511.5 \pm 20.86 \mathrm{c}$ \\
\hline Scolymus hispanicus & $34.16 \pm 0.53 \mathrm{~h}$ & $8.19 \pm 0.03 \mathrm{j}$ & $57.66 \pm 0.56 \mathrm{c}$ & $1.69 \pm 0.04 \mathrm{~b}$ & $0.85 \pm 0.00 \mathrm{a}$ \\
Silybum marianum & $43.53 \pm 0.98 \mathrm{j}$ & $3.86 \pm 0.10 \mathrm{jg}$ & $52.61 \pm 0.87 \mathrm{a}$ & $1.21 \pm 0.05 \mathrm{a}$ & $1.44 \pm 0.01 \mathrm{a}$ \\
\hline Asparagus acutifolius & $38.83 \pm 0.49 \mathrm{i}$ & $4.87 \pm 0.07 \mathrm{hi}$ & $56.30 \pm 0.56 \mathrm{bc}$ & $1.45 \pm 0.03 \mathrm{ab}$ & $3.02 \pm 0.11 \mathrm{a}$ \\
Humulus lupulus & $28.43 \pm 0.76 \mathrm{~g}$ & $2.55 \pm 0.10 \mathrm{~cd}$ & $69.02 \pm 0.85 \mathrm{de}$ & $2.43 \pm 0.10 \mathrm{c}$ & $0.78 \pm 0.02 \mathrm{a}$ \\
Tamus communis & $18.85 \pm 0.73 \mathrm{~cd}$ & $0.92 \pm 0.10 \mathrm{i}$ & $80.23 \pm 0.68 \mathrm{gh}$ & $4.26 \pm 0.20 \mathrm{fg}$ & $0.21 \pm 0.01 \mathrm{a}$ \\
Bryonia dioica & $23.95 \pm 1.20 \mathrm{ef}$ & $1.63 \pm 0.02 \mathrm{~b}$ & $74.42 \pm 1.21 \mathrm{gh}$ & $3.11 \pm 0.21 \mathrm{ef}$ & $0.10 \pm 0.00 \mathrm{a}$ \\
\hline Allium ampeloprasum & $38.23 \pm 0.63 \mathrm{i}$ & $7.61 \pm 0.44 \mathrm{j}$ & $54.16 \pm 0.29 \mathrm{ab}$ & $1.42 \pm 0.03 \mathrm{ab}$ & $99.59 \pm 5.80 \mathrm{~b}$ \\
\hline & & & & &
\end{tabular}

SFA- Saturated fatty acids; MUFA- Monounsaturated fatty acids; PUFA: Polyunsaturated fatty acids. 


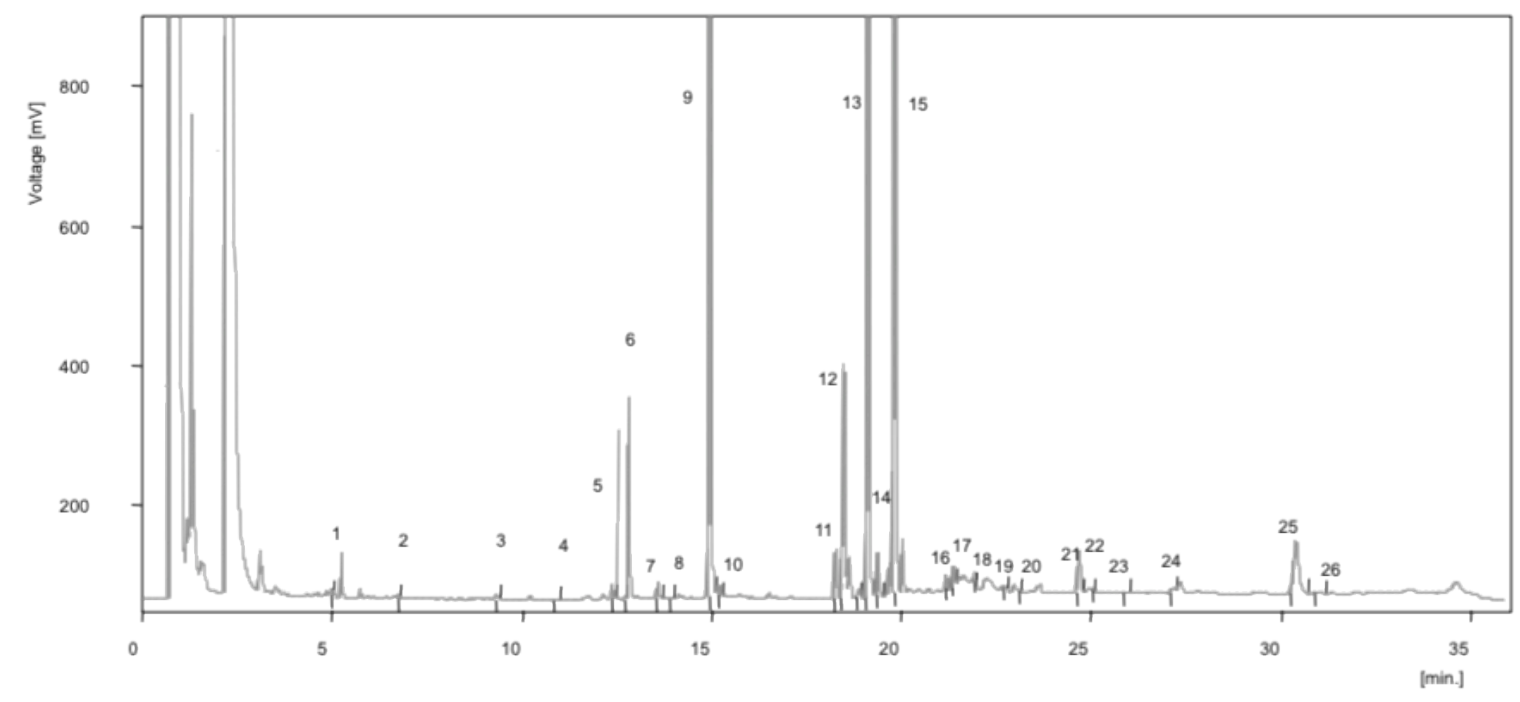

Figure 1. Fatty acids profile of Tamus communis young shoots. 1. C8:0; 2. C10:0; 3. C12:0; 4. C13:0; 5. C14:0; 6. C14:1; 7. C15:0; 8. C16:0; 9. C16:1; 10. C17:0; 11. C18:0; 12. C18:1n9c; 13. C18:2n6c; 14. C18:3n6; 15. C18:3n3; 16. C20:0; 17. C20:1c; 18. C20:2c; 19. C20:3n3+C21:0; 20. C20:5n3; 21. C22:0; 22. C22:1n9; 23. C22:2; 24. C23:0; 25. C24:0; 26. C24:1. 


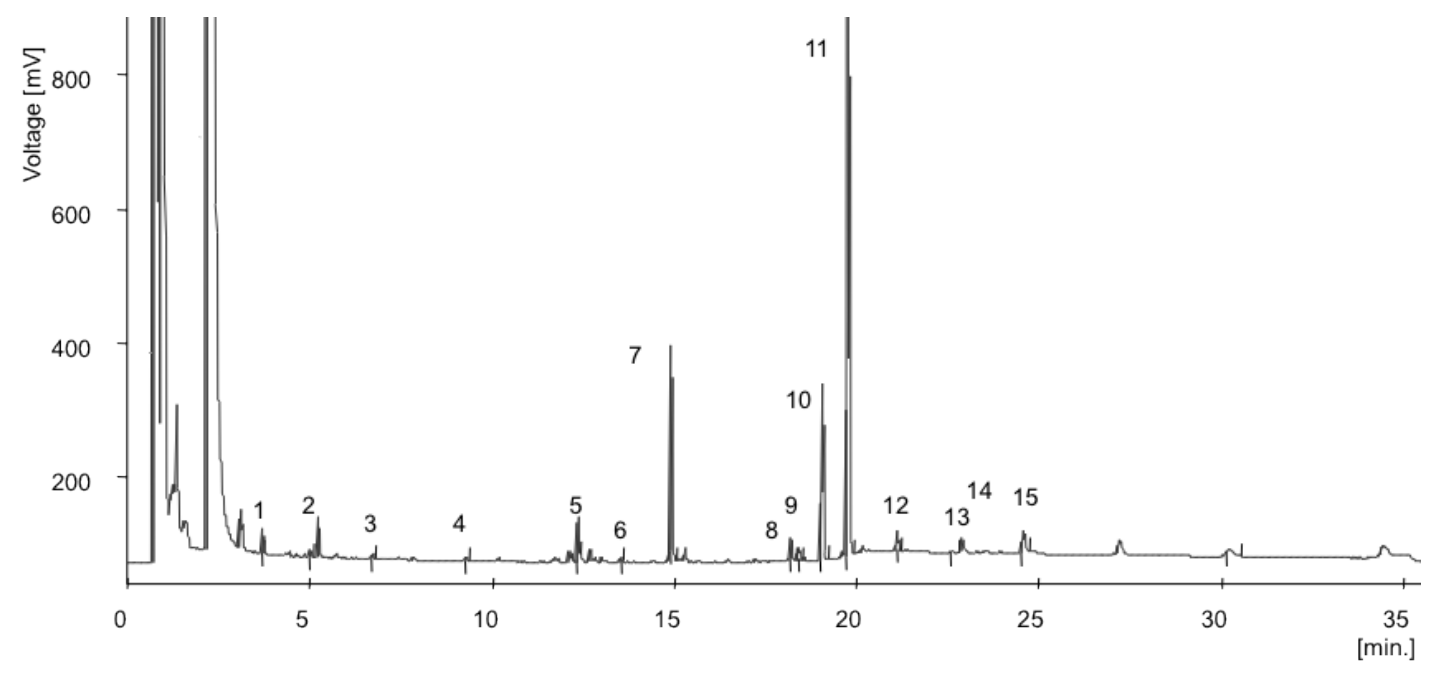

Figure 2. Fatty acids profile of Sonchus oleraceus young stems with leaves. 1. C6:0; 2. C8:0; 3. C10:0; 4. C12:0; 5. C14:0; 6. C15:0; 7. C16:0; 8. C18:0; 9. C18:1n9c; 10. C18:2n6c; 11. C18:3n6; 12. C20:0; 13. C20:3n3; 14. C21:0; 15. C21:0; 16. C24:0. 